\title{
Modifying Plant Oils for Use as Fuel in Rural Contexts Tanzania: Techno-Economic Analysis
}

\author{
Happiness Mlay, Jamidu H. Y. Katima, Ruwaichi J. A. Minja \\ College of Engineering and Technology, University of Dar es Salaam, Dar es Salaam, Tanzania \\ Email: happieus@gmail.com
}

Received 22 January 2014; revised 27 February 2014; accepted 6 March 2014

Copyright (C) 2014 by authors and Scientific Research Publishing Inc.

This work is licensed under the Creative Commons Attribution International License (CC BY). http://creativecommons.org/licenses/by/4.0/

(c) (i) Open Access

\begin{abstract}
Techno-economic analysis of a small-scale Modified Plant Oil (MPO) production plant that has an annual production capacity of 15,072,741 $\mathrm{kg}$ of MPO (batch process) was carried out to estimate the capital and operating costs of a plant. The analysis was done by using a computer model that was designed and simulated with an aid of SuperPro Designer (Version 4.32) software. The specified feedstock was crude Jatropha oil (JO) and the main product was MPO. The major processes involved were degumming, neutralisation and blending. Degumming involved the removal of gums or phospholipids, and two methods were used: water degumming and acid degumming, whereas blending involved mixing of degummed or purified JO with natural gas condensate (NGC) modifier to lower the viscosity of JO. From techno-economic analysis of the process, it was found that the total capital investment of a plant was about US $\$ 10,222,000$ and the predicted unit production cost of MPO was US $\$ 1.315 / \mathrm{kg}$ at a value of US $\$ 1.0 / \mathrm{kg}$ of JO. The economic feasibility of MPO production was found to be highly influenced by the price of feedstock, which contributed about $95 \%$ of the total annual production cost. The relationship between plant throughput and unit cost of producing MPO showed that unit production cost was very sensitive to production rate at low annual throughputs. The MPO cost showed a direct linear relationship with the cost of J0, with a change of US $\$ 0.50 / \mathrm{kg}$ of MPO in MPO cost in every change of US $\$ 0.50 / \mathrm{kg}$ of JO in JO price. The process technology simulated was found to be economically viable and can be implemented in rural setting, taking into consideration Tanzania's rural situation.
\end{abstract}

\section{Keywords}

Modified Plant Oil; Natural Gas Condensate; Jatropha Oil; Techno-Economic Analysis 


\section{Introduction}

The rural community still lacks access to clean, cost effective and sustainable form of energy that is needed to power their socio-economic activities, particularly for agriculture, water supply and food processing. Bioenergy is the main form of energy to rural residents particularly wood-fuel, which is mainly used for cooking. On one hand, use of wood-fuel for energy contributes negatively to deforestation and hence loss of $\mathrm{CO}_{2}$ sink, the quality of life due to inherent indoor air pollution and overburdening women and children as a result of walking long distances to collect wood fuel [1]. On the other hand, modern renewable energy technologies such as wind and solar are relatively expensive for rural community to adapt [2] [3]. Biofuels are considered to be potential alternative source of energy that can, if properly harnessed, enhance energy access to the rural community. Liquid biofuel such as POs can be easily processed and distributed to be accessed and utilised at village level for running diesel engines.

However, POs cannot be used directly in diesel engines because of high viscosity and low volatility as well as presence of gums and free fatty acids (FFAs), which affects engine operation and durability [4]-[15]. Some research efforts [8] [16] [17] have focused on engine modification to handle high viscosity biofuel. Modifying of PO to improve fuel properties so that it can be used without modifying an engine, could be the best way of handling the problem with the main objective of enhancing direct use of $\mathrm{PO}$ at minimum modification.

Some of the techniques used in modifying POs are such as transesterification, pyrolysis, blending and microemulsion [10]. However, selection of a suitable plant oil modification process is a function of many factors. One of the factors which may influence the choice of any process in chemical engineering includes technical factors, present and future availability of raw material for sustainable production, equipment (availability, material of construction), plant location and costs [18] [19]. Technical factors are such as the complexity of the process and performance of the process in the quality of final product as well as safety. Plant location for this case, is for a process that fits the rural situation.

In most cases, rural economy is characterised by low per capita economy and therefore the main challenge is an appropriate process that can meet low capital investment and yet ensure financial return to the investor. Moreover, some methods and technologies used, still display low performance in reduction of viscosity and removal of gums and FFAs. So the main questions to answer are what reasonable quality of PO is needed for rural setting utilisation; what measures are required to improve oil quality for use as fuel in diesel engines commonly found in remote rural environment, by analysing on which methods exist can reduce the unwanted components in the PO to an acceptable level, both small-scale, simple, low cost and applicable for the rural setting.

Quite a number of PO research publications and reports, analyses and reviews are more concerned with the technical analysis and the economic feasibility (techno-economic analysis) of biodiesel production by using transesterification reaction method [6] [13] [14] [20]-[25]. However, the cost implications of modifying PO using other methods have not been a major concern. It is therefore important to conduct a techno-economic analysis of the non-transesterification method used to modify POs.

Although techno-economic analysis on biodiesel industry has been performed by several studies to date in determining its economic prospective and profitability, in all the studies it has been found that even though biodiesel is more renewable and cleaner than fossil diesel, it has relatively high production costs which makes it not economic viable due to its price. Another major observation is that costs of feedstock comprise a very substantial part of overall biodiesel cost (about 75\% - 80\% of the total operating costs) [23] [24]. To address these obstacles, the need to either develop technologies which allow the use of low-cost and lower value feedstock or to use viable conversion process as well as the recovery of high quality glycerol has been suggested.

This highlighted the need for a flexible model to be developed, which could aid in the comparison of alternative production routes for their abilities in reducing production costs to desirable levels and making the conversion of POs into liquid biofuel which be economically viable. The developed model could assist in determining the overall economic feasibility of a proposed operation and its flexibility could guide choices regarding feedstock, plant capacity, chemical process or conversion process and design as a whole [23] since in a simulation software, all aspects of a process are accounted for simultaneously and when changes are made to one aspect of the process, the impact on all other areas is automatically determined [26].

This paper focuses on the modification of plant oil as a way of improving the fuel properties of jatropha (Jatropha Curcas) seed oil so that it can be used as a potential ready-to-use fuel in low- and medium-speed diesel engines for rural community without modifying an engine. These engines are commonly used in rural areas for 
many social economic activities. Lister engines are a good example of these engines. The main objective of this study is to evaluate techno-economic viability of a non-transesterification method or process developed to modify PO into a suitable liquid biofuel for rural setting. This involves modeling a non-existing industry based on the country's technology capacity.

\section{Modified Plant Oil (MPO) Production}

A small-scale MPO production plant that has an annual production capacity of 15,072,741 kg of MPO (batch process) was designed and simulated in SuperPro Designer. MPO production involves modifying of PO to lower and/or remove the undesired materials from PO to produce PO with fuel properties that has similar specifications of diesel fuel grade 4-D (ASTM D975), for use in low- and medium speed diesel engines. The main problems to address were viscosity, FFAs and gums (Phospholipids). Thus, the major processes involved were degumming, neutralisation and blending.

Degumming materials were water and phosphoric acid. Sodium hydroxide $(\mathrm{NaOH})$ was used for neutralisation of FFAs. The blending material used was Natural Gas Condensate (NGC), which is a by-product of natural gas extraction. The condensate is supplied by Tanzania Petroleum Development Corporation (TPDC) (Dar es Salaam, Tanzania) from Songosongo gas fields. The composition of the Songosongo natural gas condensate was as shown in Table 1 as per [27] and [28]. The condensate was water-free with the composition of FFAs of only about $0.01 \% \mathrm{w} / \mathrm{w}$.

\section{Process Description, Simulation and Plant Design}

Figure 1 shows the simulation of the entire MPO production process starting from crude jatropha oil (JO) as the feedstock specified to MPO (or modified JO) as the main product. Process simulation with SuperPro Designer software allows predicting the behaviour of a process using basic engineering relationships such as mass and energy balances, phase equilibrium and kinetics reactions. With reliable thermodynamic data, realistic operating conditions and the rigorous SuperPro Designer equipment models, the software was able to simulate the performance of an actual MPO industrial plant.

SuperPro Designer can help design better plants or process within existing plants to help increase profitability. Due to its flexibility, the software allowed interactively change of specifications such as operating conditions, flowsheet configuration and feed compositions to run new cases and analyse alternatives. SuperPro Designer is the only commercial process simulator that can handle equally well batch and continuous processes as well as combination of batch and continuous processes. More importantly, it has modelling capabilities which are suitable for this application [18] [26] [29]-[32].

The simulator includes mathematical models that perform cost analysis and project evaluation calculations. The project feasibility was assessed based on the Net Present Value (NPV) or Net Present Worth (NPW) profitability indicator. NPV can be defined as the difference amount between the sums of discounted: cash inflows and cash outflows; or the difference between total present value of annual cash flows and the total capital investment. It is a standard method for using the time value of money to appraise long-term projects [18]-[20].

Table 1. Chemical composition of songosongo natural gas condensate [27] [28].

\begin{tabular}{cccc}
\hline Component & Chemical Formula & Molar Composition [\%] & Concentration [g/l] \\
\hline Propane & $\mathrm{C}_{3} \mathrm{H}_{8}$ & 0.126 & 0.113 \\
Butane & $\mathrm{C}_{4} \mathrm{H}_{10}$ & 0.670 & 0.601 \\
Pentane & $\mathrm{C}_{5} \mathrm{H}_{12}$ & 1.262 & 1.133 \\
Hexane & $\mathrm{C}_{6} \mathrm{H}_{14}$ & 2.183 & 1.959 \\
Heptane & $\mathrm{C}_{7} \mathrm{H}_{16}$ & 24.738 & 22.147 \\
Octane & $\mathrm{C}_{8} \mathrm{H}_{18}$ & 33.883 & 30.368 \\
Nonane & $\mathrm{C}_{9} \mathrm{H}_{20}$ & 37.264 & 33.361 \\
\hline
\end{tabular}




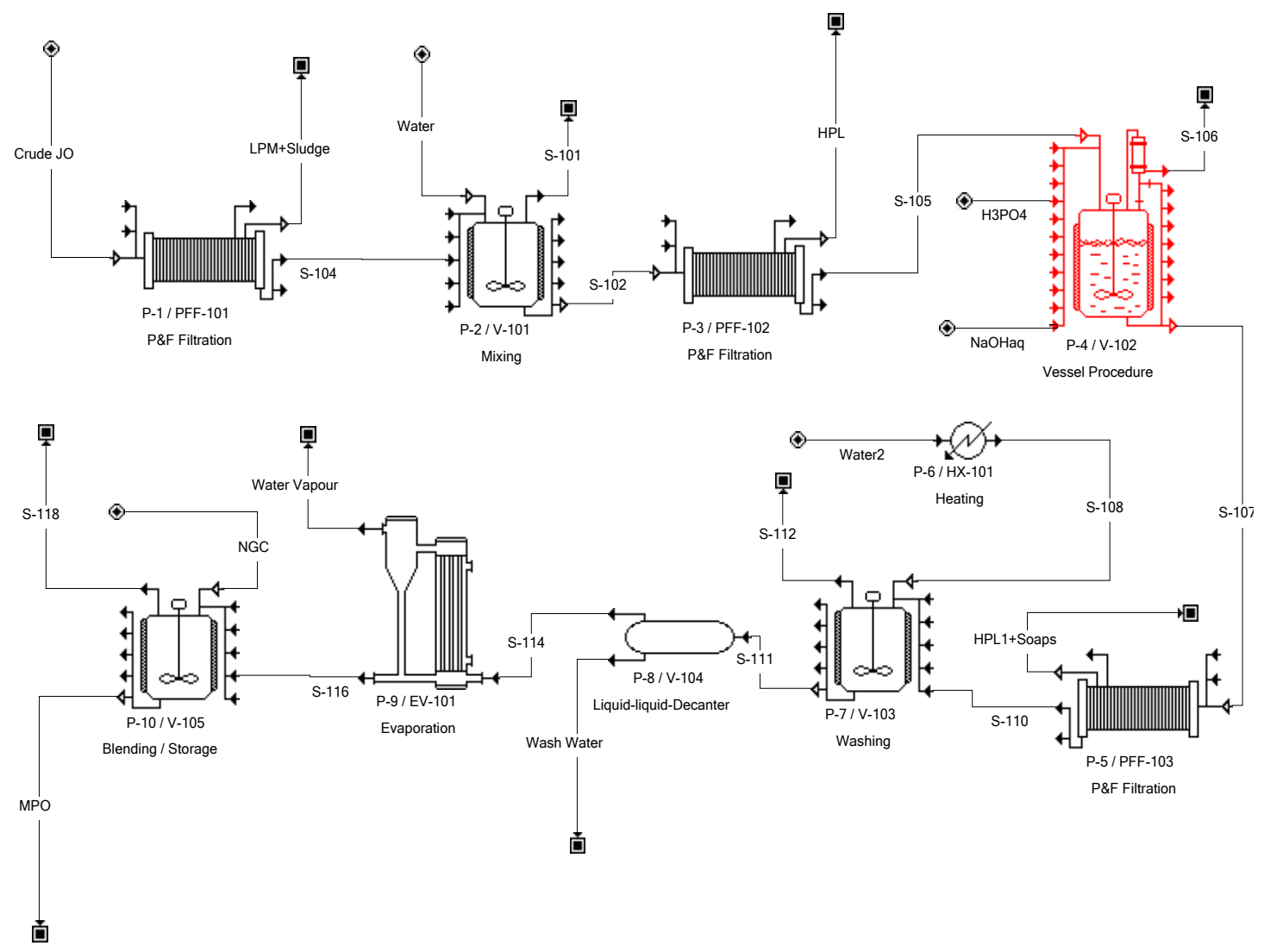

Figure 1. Process flow diagram (PFD) of MPO production obtained from superpro designer.

\subsection{Assumptions and Limitations}

The following assumptions and limitations were made in the process simulation:

1) JO is classified as a mixed TG: Oleic-Linoleic and therefore pure oil is an OOL molecule (or 1,2OLEIN-3-LINOLEIN molecule), which is very rich in oleic acid [33];

2) FFA in JO is based on oleic acid (C18:1) since the major FA composition of JO is oleic acid (34.3\% 45.8\%) [33] [34]. Oleic acid is also very common in most oils and fats;

3) Incoming crude JO may contain significant amount of solid material (light and heavy) that need to be removed and based on particle size or specific gravity, filtration or sedimentation can be applied respectively;

4) Phospholipids present in JO are of two forms: free hydratable phospholipids (HPL) and non-hydratable phospholipids (NHPL);

5) NHPL compounds are in the form of $\mathrm{Ca}^{2+}$ salts: Calcium phosphatidate (CaPA) complexes and phosphatidic acid (PA). PA is formed after initial decomposition of CaPA by the phosphoric acid [35]-[37];

6) NHPL compounds are very rich in FA common in JO;

7) This simulation will not consider the treatment of waste streams;

8) The biofuel market has developed in Tanzania and so there is high supply of JO, that makes the price of JO low;

9) A new facility plant will be constructed and

10) The plant operates around the clock.

The main things which were taken into consideration for the techno-economic analysis were the raw material, pre-treatment, transformation and separation and are described in the following subsections.

\subsection{Raw Material}

In this case, the raw material is the extracted jatropha oil (crude virgin oil). The design was based on composition of crude JO as shown in Table 2. As the oil contains gums as well as substantial amount of FFAs, treatment 
Table 2. Composition of crude JO.

\begin{tabular}{cc}
\hline Component & Composition [\% w/w] \\
\hline Water & 0.04 \\
FFA & 6.07 \\
Gums & 0.1 \\
LPM & 0.05 \\
Pure Oil & 93.69 \\
Sludge & 0.05 \\
Total & $\mathbf{1 0 0}$ \\
\hline
\end{tabular}

was needed to lower or remove these substances. The process components accounted for simulation were oil filters, blending tanks, a reactor, a decanter and an evaporator.

\subsection{Pre-Treatment}

Crude JO with composition presented in Table 2 is fed into the first filter. In the first blending tank, water is added and is mixed with clear oil to perform water degumming for the removal of HPL.

\subsection{Transformation}

In the reactor, acid (or chemical) degumming and neutralisation takes place to remove NHPL and FFAs from the water-degummed oil before sending it to the third blending tank for blending to lower the viscosity. Phosphoric acid converts NHPL to HPL ones (acid degumming) (Figure 2).

Aqueous sodium hydroxide is charged in the same reactor, to convert FFA to soap (neutralisation) (Figure 3). Other acidic substances present in the reactor also react with sodium hydroxide solution. However, the MPO product itself is a typical non-transformed product since the conversion pathways does not lead to the TGs molecules breakdown or synthesis of new ones. The chemical reaction takes place for the transformation of oil impurities only to facilitate their removal. Thus, after removal of FFAs and gums, the refined oil which is still viscous is blended with NGC to lower the JO viscosity. NGC modifier is added to a pure dried JO and the two components are blended to form the product modified plant oil (MPO). The degumming and neutralisation reactions taking place in the reactor are as shown in Figure 2 and Figure 3.

\subsection{Separation}

In the first filter, clear oil is separated from the light particulate matter (LPM), sludge (and some water) and any other impurities. During water degumming the HPL are hydrated with water, swells and form precipitates or gels, which are separated from clear oil by the second filter. The salts formed in the reactor as well as any other impurities are removed together with soaps and phosphatides in the third filter. In the second blending tank, water (water2) is added into the neutral oil which has been separated from soaps to wash remaining soaps or any other impurities and is removed by the liquid-liquid phase decanter before blending, to avoid phase separation problem. Water used for washing neutral oil (water2) is typical municipal quality water. The neutral oil may still contain some water after decantation. This must be lowered to a maximum of $0.5 \%(\mathrm{v} / \mathrm{v})$ to meet diesel fuel (grade 4-D) specifications (ASTM D975), and is removed by evaporation.

In large scale production, the solids from water degumming and from the reactor can be separated by centrifugation. The co-product soaps (in the neutralisation step) can be sent to a storage tank for other uses instead of disposing them as waste. The other co-product(s) were sludge, LPM, wet gums, water vapour and wastewater from the washing unit. Water vapour can also be condensed and recovered; wastewater can be treated and all this water, that is, the recovered water vapour and treated wastewater can be recycled.

\subsection{Operational Parameters}

Table 3 shows operational data input of the simulation. Most of these data were Laboratory data or experimental results obtained in this study and adopted to the process simulation. Also literature and various technical sources 


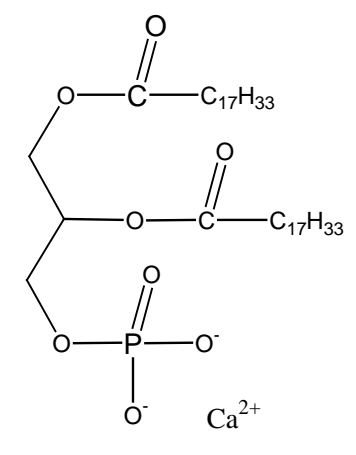

Calcium salt of phosphatidic acid(NHPL)

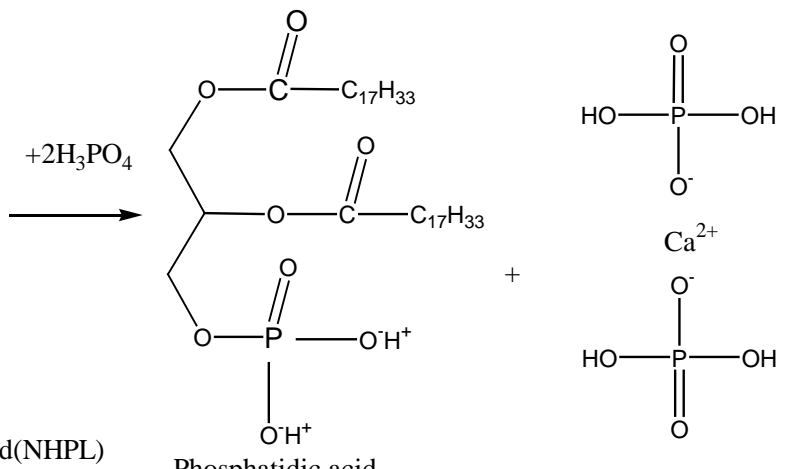

Phosphatidic acid

Calcium bi-phosphate

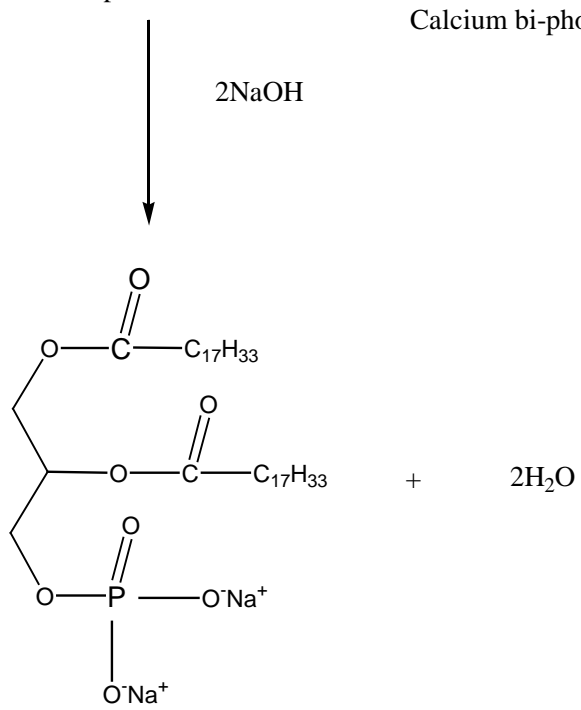

Hydratable sodium salt

Figure 2. Acid Degumming and partial neutralisation [36].

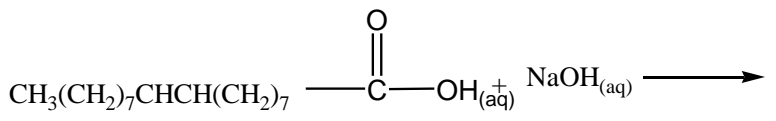

FFA(Oleic acid)

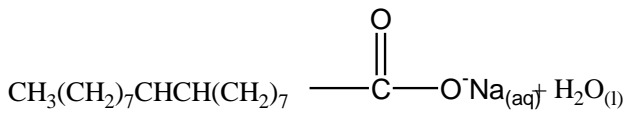

Soap

\section{Figure 3. Saponification or neutralisation reaction.}

including engineering firms that provide liquid biofuel processing expertise, chemical or equipment suppliers, researchers and practitioners experienced with the topic under study were used to obtain the necessary parameters or operational data for each unit operation.

Table 4 presents materials involved in the process. It includes entering and leaving materials or reactants and products as well as by-products formed during the process. Figure 4 and Figure 5 are the chemical structures of the OOL (or 1,2-OLEIN-3-LINOLEIN) molecule and oleic acid respectively. The chemical structures, chemical formulas and properties of OOL and oleic acid were supplied by Chemical Book [38] and the Nist WebBook [39] respectively. 
Table 3. Operational data.

\begin{tabular}{cccc}
\hline Name & Data Input (Amount/Value) & $\begin{array}{c}\text { Operational Condition } \\
\text { (Temperature) }\end{array}$ & Equipment/Stream \\
\hline $\begin{array}{c}\text { Crude JO: Base Total Flowrate } \\
\text { Crude JO: Composition }\end{array}$ & 5000 l/batch (or $4600 \mathrm{~kg} / \mathrm{batch})$ & $30 \pm 1^{\circ} \mathrm{C}($ Room Temp.) & Fed to PFF-101 \\
Water & Ref. Table 2 & $30^{\circ} \mathrm{C} \pm 1^{\circ} \mathrm{C}$ & Fed to PFF-101 \\
Pure oil & $5 \%$ by volume of oil & $30^{\circ} \mathrm{C} \pm 1^{\circ} \mathrm{C}$ & Added to V-101 \\
Phosphoric Acid & -- & $80^{\circ} \mathrm{C} \pm 1^{\circ} \mathrm{C}$ & In the V-102 \\
Sodium Hydroxide & $0.2 \%$ by volume of oil & -- & Charged to V-102 \\
Water2 & 3.5 g/l of oil & -- & Charged to V-102 \\
Pure oil & $40 \%$ by volume of oil & $50^{\circ} \mathrm{C} \pm 1^{\circ} \mathrm{C}$ & Leaving HX-101; Added to \\
Pure oil & -- & $140^{\circ} \mathrm{C} \pm 1^{\circ} \mathrm{C}$ & V-103 the EV-101 \\
NGC & -- & $30^{\circ} \mathrm{C} \pm 1^{\circ} \mathrm{C}$ & In the V-105 \\
Added to V-105
\end{tabular}

Table 4. Process components: reactants and products.

\begin{tabular}{|c|c|c|}
\hline Name & Chemical Formula & Remarks \\
\hline $\begin{array}{l}\text { Jatropha oil (JO): } \\
\text { 1,2-OLEIN -3-LINOLEIN molecule } \\
\text { (OOL) }\end{array}$ & $\mathrm{C}_{57} \mathrm{H}_{102} \mathrm{O}_{6}$ & $\begin{array}{l}\text { The major triglyceride (TG) molecule in JO [33]: Main feedstock: Is not } \\
\text { transformed in the reactor }\end{array}$ \\
\hline Sodium Hydroxide & $\mathrm{NaOH}$ & $\begin{array}{l}\text { Converting FFA into soap; Partial Neutralisation of Phosphatidic acid } \\
\text { (PA)/Hydrating PA }\end{array}$ \\
\hline Oleic acid & $\mathrm{C}_{18} \mathrm{H}_{34} \mathrm{O}_{2}$ & $\begin{array}{l}\text { The principal FA in the JO [33] [34]: exist in crude JO as a deterioration } \\
\text { by-product of hydrolysis }\end{array}$ \\
\hline Phosphoric Acid & $\mathrm{H}_{3} \mathrm{PO}_{4}$ & Removing gums by converting NHPL to HPL \\
\hline Phosphatidic acid (PA) & $\mathrm{C}_{39} \mathrm{H}_{73} \mathrm{O}_{8} \mathrm{P}$ & Gums (NHPL): Intermediate product of acid degumming \\
\hline Calcium phosphatidate (CaPA) & $\mathrm{C}_{39} \mathrm{H}_{72} \mathrm{O}_{8} \mathrm{PCa}$ & $\begin{array}{l}\text { Gums: NHPL compounds in the form of } \mathrm{Ca}^{2+} \text { salts: Calcium salt of PA. } \\
\text { Main reactant in acid degumming }\end{array}$ \\
\hline Calcium bi-phosphate salt (CBP) & $\mathrm{CaH}_{4} \mathrm{P}_{2} \mathrm{O}_{8}$ & By-product of acid degumming \\
\hline Sodium salt & $\mathrm{C}_{39} \mathrm{H}_{72} \mathrm{O}_{8} \mathrm{PNa}$ & $\begin{array}{l}\text { Gums (HPL): Sodium salt of PA. Product of partial neutralisation reaction } \\
\text { of PA }\end{array}$ \\
\hline Soap & $\mathrm{C}_{18} \mathrm{H}_{33} \mathrm{O}_{2} \mathrm{Na}$ & Product of neutralisation reaction of oleic acid (transformed FFAs) \\
\hline NGC & $\begin{array}{l}\text { A mixture of hydrocarbons } \\
\left(\mathrm{C}_{3}-\mathrm{C}_{9}\right) \text {, mainly heptane, } \\
\text { octane and nonane }\end{array}$ & Modifier: Lowers JO viscosity \\
\hline MPO & $\begin{array}{l}\text { Blended oil: a mixture of } \\
\text { PO and modifier }\end{array}$ & Modified Plant Oil: Main product: a mixture of JO and NGC \\
\hline Water & $\mathrm{H}_{2} \mathrm{O}$ & $\begin{array}{l}\text { Secondary product of neutralisation reaction; hydrates (dissolves) HPL to } \\
\text { facilitate gums removal; washing material }\end{array}$ \\
\hline
\end{tabular}

\section{Simulation Results}

The results of simulation were presented in the form of reports which were generated and saved in a temporary file in the SuperPro Designer. They were then exported to a Microsoft Excel 2007 for ease of access. There are several reports generated; each focusing on a different topic. However, only Economic Evaluation Report (EER) 


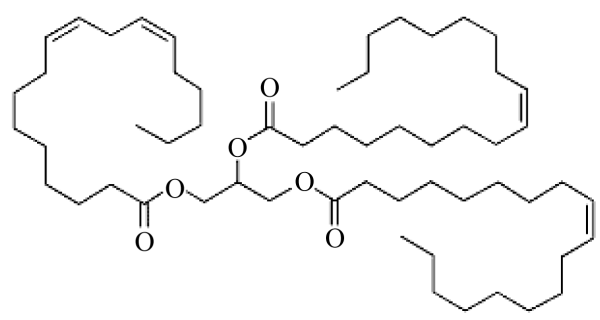

Figure 4. 1,2-OLEIN-3-LINOLEIN chemical structure.

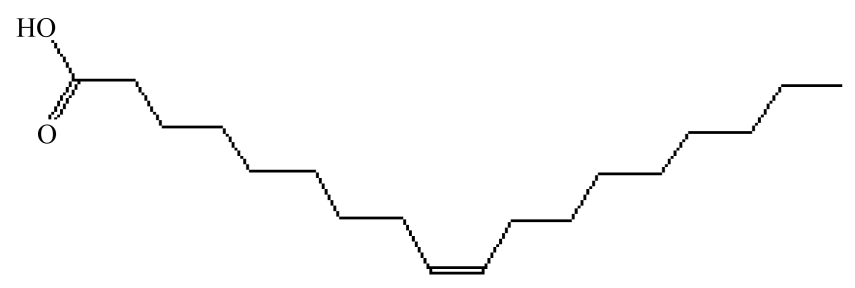

Figure 5. Oleic acid chemical structure.

and Throughput Analysis Report (THR) were presented in this paper, which provided mass balances, energy balances and economic evaluation results.

\subsection{Process Scheduling}

Scheduling and execution of batch operations were visualised by the equipment utilisation chart (Figure 6) and the Gantt chart (Figure 7) generated by the SuperPro.

On one hand, Gantt chart provides access to all simulation data for every operation in every procedure provided that it is included in the scheduling. This enables easy modifications to some operating conditions and to re-compute the execution plan. Equipment utilisation chart on the other hand, displays the utilisation of the various equipment items as a function of time for a single or multiple batches (Intelligen, 2013).

The charts shows that the execution of the various process steps as a function of time for about thirty hours (30 h) produced seven (7) consecutive batches. This is well visualised in Figure 7. The overall batch time was approximately 15 hours (Figure 7) although the effective batch time was around 2 hours. This was determined by the time bottleneck equipment, which is the equipment with the least idle time between consecutive batches. In this case, the reactor (V-102) was the time bottleneck equipment. Idle time is represented by the white space between bars in Figure 6 .

\subsection{Mass Balances}

Table 5 provides overall process data that was extracted from the Excel version of the Throughput Analysis Report (THR). It was assumed that this plant operates around the clock and the maximum annual operating time is $7919 \mathrm{~h}$ (330 days). On an annual basis, the plant processes 3249 batches and produces approximately 15,072,741 kg of MPO (4639 kg/batch) (Table 5).

\subsection{Cost analysis and Economic Evaluation}

Cost analysis and project evaluation calculations were extracted from the Excel version of the EER. Table 6 and Table 7 show detailed results on cost analysis. The amount of raw material was calculated based on the material balances. The unit cost was retrieved from the component database in the program. However, purchasing prices of some materials was assigned manually. From Table 6, the crude JO expense represents roughly 95\% of the total raw material cost.

The cost of JO was set US $\$ 1.0 / \mathrm{kg}$ by assuming that the biofuel market has been developed in Tanzania and so there is high supply of JO. The average retail price of JO in an under developed biofuel market situation in Tanzania is about TShs. 4000/L ( US \$ 2.5 up to 18th November 2013). The cost of NGC set was based on 


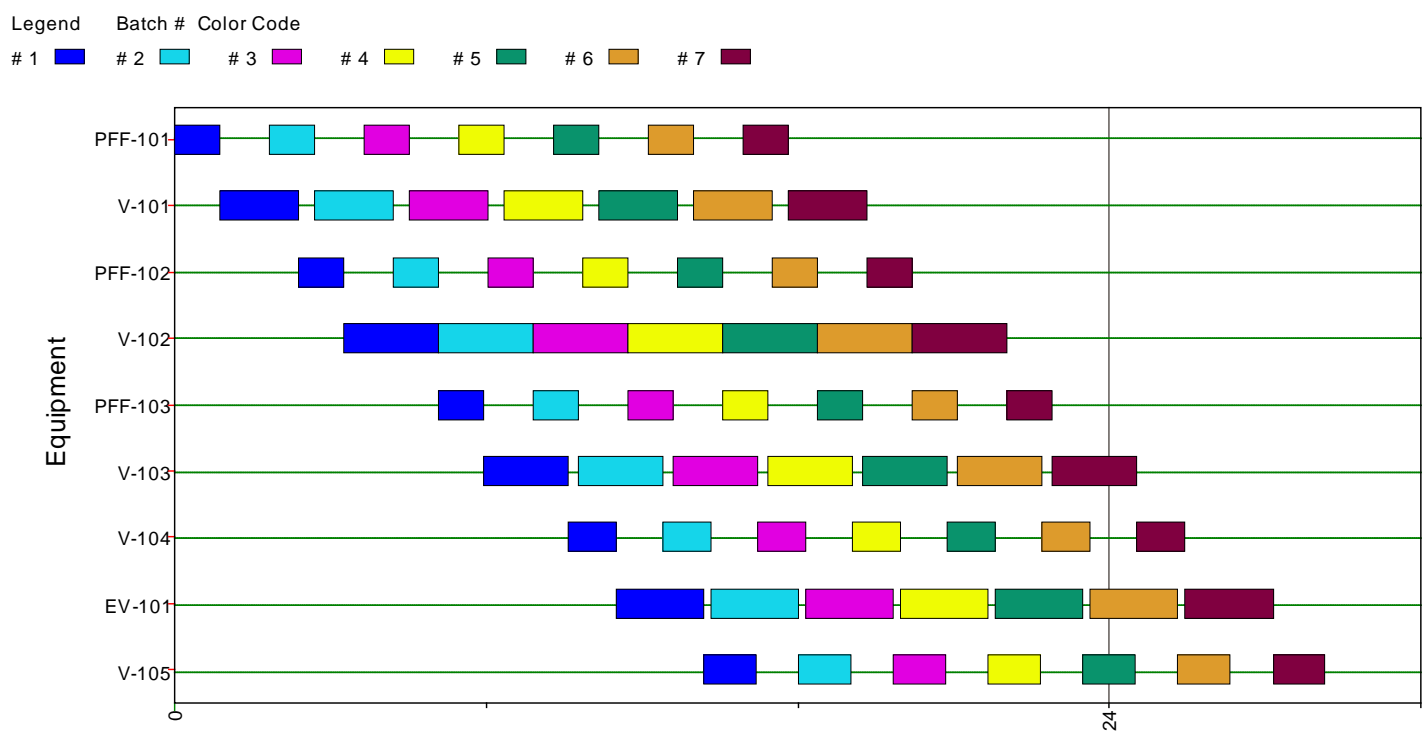

Time in $\mathrm{h}$

Figure 6. Equipment utilisation chart.

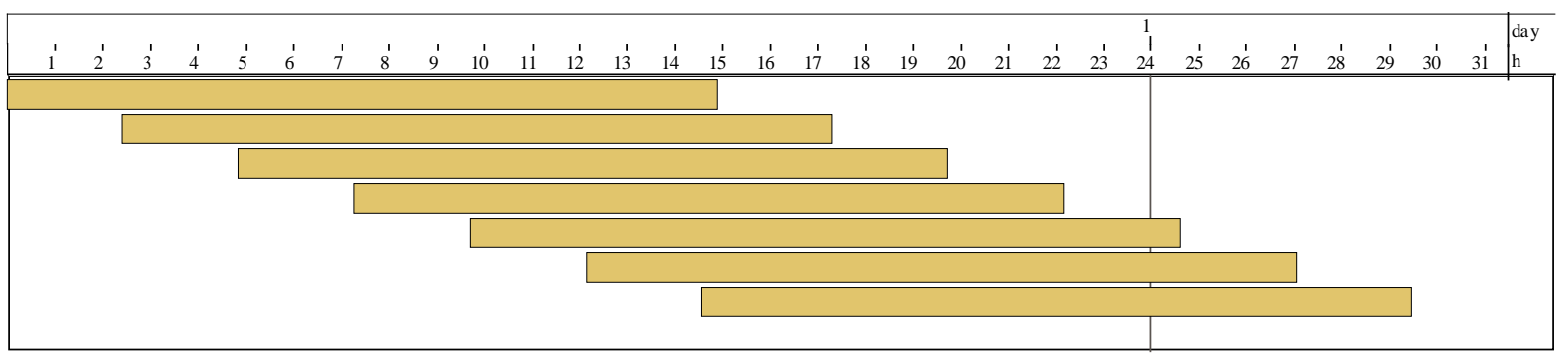

Figure 7. Gantt chart.

Table 5. Overall process data.

\begin{tabular}{ccc}
\hline Category & Value & Units \\
\hline Annual Operating Time & 7919.3 & $\mathrm{~h}$ \\
Annual Throughput & 15072740.63 & $\mathrm{~kg} \mathrm{MP}$ \\
Batch Throughput & 4639.19 & $\mathrm{~kg} \mathrm{MP}$ \\
Plant Batch Time & 14.93 & $\mathrm{~h}$ \\
Effective Plant Batch Time & 2 & $\mathrm{~h}$ \\
Number of Batches Per Year & 3249 & \\
Time Bottleneck Equipment & V-102 \\
MP = Main Product = Total Flow in MPO
\end{tabular}

Table 6. Raw materials cost summary.

\begin{tabular}{|c|c|c|c|c|}
\hline Raw Material & Unit Cost [\$/kg] & Annual Amount [kg] & Cost $[\$ / y r]$ & $\%$ \\
\hline Phosphoric Acid & 1.000 & 2794.14 & 2794 & 0.02 \\
\hline Water & 0.375 & 877230 & 328961 & 2.1 \\
\hline Sodium Hydroxide & 0.700 & 129960 & 90972 & 0.58 \\
\hline JO & 1.000 & 14945400 & 14945400 & 95.19 \\
\hline Water2 & 0.001 & 5978160 & 2989 & 0.02 \\
\hline NGC & 0.220 & 1494540 & 328799 & 2.09 \\
\hline TOTAL & & 23428084.14 & 15700000 & 100 \\
\hline
\end{tabular}


Table 7. Annual operating cost-summary (2013 prices).

\begin{tabular}{ccc}
\hline Cost Item & \$/Year & \% \\
\hline Raw Materials & 15700000 & 79.23 \\
Labor-Dependent & 2242000 & 11.31 \\
Equipment-Dependent & 1534000 & 7.74 \\
Laboratory/QC/QA & 336000 & 1.7 \\
Consumables & 0 & 0 \\
Waste Treatment/Disposal & 0 & 0 \\
Utilities & 2000 & 0.01 \\
Transportation & 0 & 0 \\
Miscellaneous & 0 & 0 \\
Advertising and Selling & 0 & 0 \\
Running Royalties & 0 & 0 \\
Failed Product Disposal & 0 & 0 \\
TOTAL & $\mathbf{1 9 8 1 4 0 0 0}$ & $\mathbf{1 0 0}$ \\
\hline
\end{tabular}

Where: QC = Quality Control and QA = Quality Assurance.

TPDC selling price, which is about TShs. 350/L ( US \$ 0.22 up to 18th November 2013) at commercial scale. The cost of phosphoric acid was set US \$ $1.0 / \mathrm{kg}$ with aid from chemical suppliers and contributed only $0.02 \%$ of the total raw material cost.

Table 7 was also generated by the software and displays other operating costs, which usually consist of costs of consumables, cost of utilities (heating, cooling and power), the cost of waste treatment and disposal. Generally, Table 7 gives a summary of the annual operating costs. As can be seen from this table, raw materials costs contributed $79.2 \%$ of the total annual operating cost [of which about $95 \%$ of it was feedstock (crude JO) expenses-from Table 6], followed by labour-dependent (11.3\%), equipment (7.7\%) while utilities contribute only $0.01 \%$ of the total annual operating cost. These results are consistent with the results presented from other analyses on liquid biofuel production [23] [24] since in most biodiesel production processes, the costs of feedstock, is found to be the major factor affecting the economic feasibility of biodiesel production process and is found to contribute about $75 \%-80 \%$ of the total operating costs.

The equipment-dependent costs for this process were based on depreciation, maintenance, and miscellaneous equipment expenses. Labour costs were based on the sum of the labour requirements for each unit procedure multiplied by a fixed labour rate (which was based on a basic labour rate, plus adjustments for fringe benefits, administration, and others). Utility costs were based on the type of heat transfer agent used, and the heating/ cooling requirements.

However, the essential results of cost analysis for the entire flow sheet of a plant with annual production capacity of 15,072,741 kg of MPO are shown in Table 8. The analysis was based on assumption that a new facility will be constructed for this process with a construction time of 15 months set and a 15 years project lifetime.

Table 8 gives an overview of the total economic impact of the plant, including the total capital investment, yearly revenues, and rate of return. This information (along with additional data) also appears in the Executive Summary dialog. The NPV is an indicator of how much value an investment adds to the firm [19] [40]. In this case, NPV is positive (i.e. NPV >0) (Table 8), it means that the investment would add value to the firm and therefore the project is economically viable and may be accepted and implemented. To calculate the revenue for this process, US $\$ 1.8 / \mathrm{kg}$ of the MPO price was assumed.

\section{Sensitivity Analysis Results}

Sensitivity analysis results showed the impact of changing specifications such as operating conditions, flowsheet configuration and feed compositions. The two new cases or scenarios were analysed as alternatives: First scenario: the impact of feedstock price fluctuations on MPO predicted price using the process model simulated pro- 
Table 8. Executive summary (2013 prices).

\begin{tabular}{ccc}
\hline Category & Value & Units \\
\hline Total Capital Investment & $10,222,000$ & $\$$ \\
Capital inv. Charged to This Project & $10,222,000$ & $\$ /$ year \\
Operating Cost & $19,814,000$ & $\mathrm{~kg} /$ year of MPO \\
Production Rate & $15,072,741$ & $\$ / \mathrm{kg}$ of MPO \\
Unit Production Cost & 1.315 & $\$ /$ year \\
Total Revenues & $27,131,000$ & $\%$ \\
Gross Margin & 26.97 & $\%$ \\
Return on Investment (ROI) & 57.71 & years \\
Payback Time (PBP) & 1.73 & $\%$ \\
Internal Rate of Return (IRR) after Taxes & 47.27 & $\$$ \\
Net Present Value (NPV) (at 7.0\% interest)
\end{tabular}

ducing 15,072,741 kg of MPO annually. Second scenario: the predicted unit cost of producing MPO of the adjusted annual production. This scenario simulated the impact of plant capacity to economic feasibility of MPO production.

\subsection{Fluctuation of Feedstock Price}

The MPO cost showed a direct linear relationship with the cost of JO (Figure 8), with a change of US $\$ 0.5 / \mathrm{kg}$ of MPO in MPO cost in every change of US $\$ 0.5 / \mathrm{kg}$ of JO in JO price. This observation is consistent with [23] observation on estimation of biodiesel production costs. However, this relationship in Figure 8 cannot be used to different kind and quality of feedstock other than crude JO of quality presented in this study.

\subsection{Plant Throughput Adjustments}

Figure 9 shows the relationship between the plant throughput, the production rate and the unit cost of producing MPO. It was as observed that the unit cost of producing MPO decreases as the annual throughputs increases. The trend in Figure 9 indicates that, the unit production cost was very sensitive to production rate at low annual throughputs (of less than $20,000 \mathrm{~kg} / \mathrm{y}$ ) while at higher annual throughputs, the cost was relatively insensitive to production rate. This shows that production scale had significant impact on the unit production cost of MPO.

\section{Conclusion}

From Techno-economic analysis performed, the total capital investment of a plant with annual production capacity of $15,072,741 \mathrm{~kg}$ of MPO is about US \$10,222,000 (or US \$ $10.2 \mathrm{M}$ ) with a PBP of 1.7 years and the predicted unit production cost of MPO is US \$1.315/kg at a value of US \$1.0/kg of JO. The economic feasibility of MPO production is found to be influenced mainly by the price of feedstock, which contributes about $95 \%$ of the total annual production cost. Others are plant capacity, price of the product (MPO) and the conversion route used. These results are consistent with the results presented from other analyses on liquid biofuel production. The analysis indicates that the process technology simulated is economically viable and can be implemented in rural setting, taking into consideration Tanzania's rural situation. The simulated model is flexible in terms of scale and process. Alternative scale or process pathways can be easily introduced to modify and assess the impacts for example that changes can have on capital and production costs. The multiple results available can then be used to find those scenarios or production systems that exhibit better performance. It also serves as the basis for future work with different POs or feedstocks. SuperPro Designer analytical tool enables a wide range of process configurations that are adapted to meet Tanzania's conditions to be simulated within a short time.

\section{Acknowledgements}

The Authors acknowledge the financial support provided by the Policy Innovation Systems for Clean Energy 


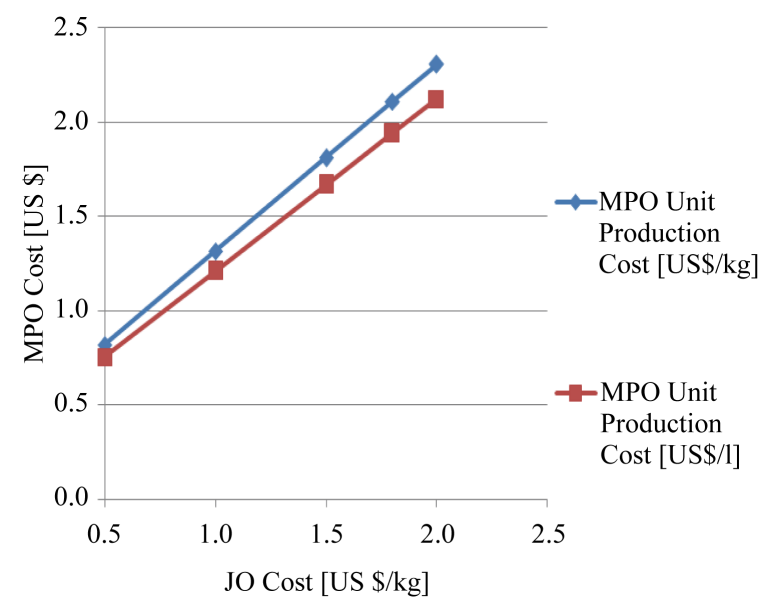

Figure 8. Relationship between JO price and MPO unit production cost.

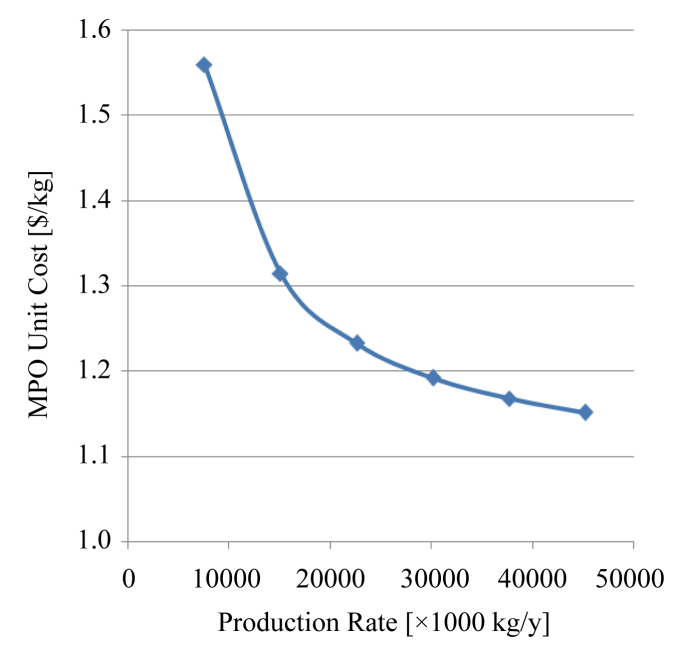

Figure 9. Relationship between production scale and unit cost.

Security (PISCES) research project, which was a five-year initiative project funded by the UK's Department for International Development (DFID). PISCES which had partners in Kenya, India, Sri Lanka, United Kingdom and Tanzania was intended to provide policymakers with information and approaches that they can apply to unlock the potential of bioenergy to improve energy access and livelihoods in poor communities. The Authors also acknowledge the Department of Chemical and Mining Engineering, University of Dar es Salaam for their co-support in this work as well as Tanzania Petroleum Development Corporation (TPDC) for supplying the natural gas condensate (NGC).

\section{References}

[1] UN Report (2007) Small-Scale Production and Use of Liquid Biofuels in Sub-Saharan Africa: Perspective for Sustainable Development. http://www.un.org/esa/sustdev/csd/csd15/documents/csd15_bp2.pdf

[2] Kimambo, C.Z.M. (2006) Solar Energy: Utilisation Status and Constraints in Tanzania. Energy Resources in Tanzania, 1, 2-37.

[3] Nzali, A.H. and Mushi, S.J.S. (2006) Wind Energy Application in Tanzania. Energy Resources in Tanzania, 1, 38-72.

[4] Lujaji, F., Bereczky, A., Novak, Cs. and Mbarawa, M. (2010) Cetane Number and Thermal Properties of Croton Oil, Biodiesel, 1-Butanol and Diesel Blends. Proceedings of the World Congress on Engineering 2010 Volume III WCE 2010, London, 30 June-2 July 2010. 
[5] Murugesan, A., Umarani, C., Chinnusamy, T.R., Krishnan, M., Subramanian, R. and Neduzchezhain, N. (2009) Production and Analysis of Biodiesel from Non-Edible Oils: A Review. Renewable and Sustainable Energy Reviews, 13, 825-834. http://dx.doi.org/10.1016/j.rser.2008.02.003

[6] Balat, M. and Balat, H. (2008) A Critical Review of Biodiesel as a Vehicular Fuel. Energy Conversion and Management, 49, 2727-2741. http://dx.doi.org/10.1016/j.enconman.2008.03.016

[7] Fürstenwerth, D., Tragsdorf, M. and Zieroth, G. (2008) Potentials of Coconut Oil as Diesel Substitute in Pacific Island Countries. www.sopac.org/tiki-download_file.php?fileId=1184

[8] Sanga, G.A. and Meena, S.B. (2008) Biofuel Powered Energy Service Platforms for Rural Energy Services: Design, Installation, Operation, Maintenance and Management. PENplus Ltd., Dar es Salaam.

[9] Shahid, E.M. and Jamal, Y. (2008) A Review of Biodiesel as Vehicular Fuel. Renewable and Sustainable Energy Reviews, 12, 2484-2494. http://dx.doi.org/10.1016/j.rser.2007.06.001

[10] Mittelbach, M. and Remschmidt, C. (2004) Biodiesel: The Comprehensive Handbook. Boersedruck Ges.m.b.H, Vienna.

[11] de Almeida, S.C.A., Belchior, C.R., Nascimento, M.V.G., Vieira, L.D.S.R. and Fleury, G. (2002) Performance of a Diesel Generator Fuelled with Palm Oil. Fuel, 81, 2097-2102. http://dx.doi.org/10.1016/S0016-2361(02)00155-2

[12] Altin, R., Cetinkaya, S. and Yücesu, H.S. (2001) The Potential of Using Vegetable Oil Fuels as Fuel for Diesel Engines. Energy Conversion and Management, 42, 529-538. http://dx.doi.org/10.1016/S0196-8904(00)00080-7

[13] Srivastava, A. and Prasad, R. (2000) Triglycerides-Based Diesel Fuels. Renewable and Sustainable Energy Reviews, 4, 111-133. http://dx.doi.org/10.1016/S1364-0321(99)00013-1

[14] Ma, F. and Hanna, M.A. (1999) Biodiesel Production: A Review. Bioresource Technology, 70, 1-15. http://dx.doi.org/10.1016/S0960-8524(99)00025-5

[15] Nwafor, O.M.I. and Rice, G. (1996) Performance of Rapeseed Oil Blends in a Diesel Engine. Applied Energy, 54, 345354. http://dx.doi.org/10.1016/0306-2619(96)00004-9

[16] kleinová, A., Vailing, I., Lábaj, J., Mikulec, J. and Cvengroš, J. (2011) Vegetable Oils and Animal Fats as Alternative Fuels for Diesel Engines with Dual Fuel Operation. Fuel Processing Technology, 92, 1980-1986. http://dx.doi.org/10.1016/j.fuproc.2011.05.018

[17] Basinger, M., Reding, T., Williams, C., Lackner, K.S. and Modi, V. (2010) Compression Ignition Engine Modifications for Straight Plant Oil Fuelling in Remote Contexts: Modification Design and Short-Run Testing. Fuel, 89, 29252938. http://dx.doi.org/10.1016/j.fuel.2010.04.028

[18] Sinnott, R.K. (1993) Coulson and Richardson's Chemical Engineering (Design). Chemical Engineering Technical Series. 2nd Edition, Pergamon Press, Oxford, New York, Seoul, Tokyo.

[19] Peters, M.S. and Timmerhaus, K.D. (1981) Plant Design and Economics for Chemical Engineers. Chemical Engineering Series. 3rd Edition, McGraw-Hill, Tokyo.

[20] Vlysidis, A., Binns, M., Webb, C. and Theodoropoulos, C. (2011) Integrated Biodiesel Plants: Options and Perspectives. http://www.nt.ntnu.no/users/skoge/prost/proceedings/pres2011-an-ic...

[21] Demirbas, A. (2009) Political, Economic and Environmental Impacts of Biofuels: A Review. Applied Energy, 86, S108-S117. http://dx.doi.org/10.1016/j.apenergy.2009.04.036

[22] Demirbas, A. (2008) Biofuels Sources, Biofuel Policy, Biofuel Economy and Global Biofuel Projections. Energy Conversion and Management, 49, 2106-2116. http://dx.doi.org/10.1016/j.enconman.2008.02.020

[23] Haas, M.J., Mcaloon, A.J., Yee, W.C. and Foglia, T.A. (2006) A Process Model to Estimate Biodiesel Production Costs. Bioresource Technology, 97, 671-678. http://dx.doi.org/10.1016/j.biortech.2005.03.039

[24] Zhang, Y., Dubé, M.A., Mclean, D.D. and Kates, M. (2003) Biodiesel Production from Waste Cooking Oil: 2. Economic Assessment and Sensitivity Analysis. Bioresource Technology, 90, 229-240. http://dx.doi.org/10.1016/S0960-8524(03)00150-0

[25] Knothe, G., Dunn, O.R. and Bagby, O.M. (1997) Biodiesel: The Use of Vegetable Oils and their Derivatives as Alternative Diesel Fuels. Agriculture Research Service. www.journeytoforever.org/biofuel_library/VegetableOilsKnothe.pdf

[26] Shanklin, T., Marten, M.R., Roper K. and Yegneswaran, P.K. (2001) Evaluation of Process Simulation Software for Biotechnology Application. http://www.pharmaceuticalonline.com/doc/Evaluation-of-Process-Simulation-Software-for-0001

[27] Tanzania Petroleum Development Corporation (2011) Utilisation of the Songosongo Natural Gas Condensate. TPDC and UDSM-PISCES Meeting, BWM Towers TPDC Offices, Dar es Salaam, 18 May 2011. Unpublished.

[28] Rajabu, Y.R., Manyele, S.V. and Mrema, G.D. (2009) Utilisation of the Songosongo Gas Condensate. Final Year Project, Chemical and Mining Engineering, University of Dar es Salaam, Dar es Salaam. 
[29] Intelligen, Inc. (2013) http://www.intelligen.com

[30] Yee, W.C., Mcaloon, A.J. and Tomasula, P.M. (2013) Manual for the Fluid Milk Process Model and Simulator. http://www.idfa.org/files/resources/dairy-process-manual-ver3-pmt-may-2013a.pdf

[31] Saska, M. (2009) Modelling Boiling House Operations with SuperPro Designer: Effects of Final Molasses Recycle and Double Magma Boiling. http://sugaryazucar.com/yahoo_site_admin/assets/docs/Modelling_boiling_house_operations_with_SuperPro_Designer .110110305.pdf

[32] Bowen, E., Kennedy, S.C. and Miranda, K. (2010) Ethanol from Sugar Beets: A Process and Economic Analysis. http://www.scribd.com/doc/77393730/Ethanol-From-Sugar-Beets-A-Process-and-Economic-Analysis

[33] Akbar, E., Yaakob, Z., Kamarudin, S.K., Ismail, M. and Salimon, J. (2009) Characteristic and Composition of Jatropha curcas Oil Seed from Malaysia and Its Potential as Biodiesel Feedstock. European Journal of Scientific Research, 29, 396-403.

[34] Diligent Tanzania (2010) Material Safety Data Sheet, Diligent Jatropha Seed Oil. http://www.diligent-tanzania.com

[35] Dijkstra, A.J. (2011) Edible Oil Processing-Refining - Introduction to Degumming. The AOCS Lipid Library. http://lipidlibrary.aocs.org/processing/degum-intro/index.htm

[36] Deffense, E. (2009) From Organic Chemistry to Fat and Oil Chemistry. Oleagineux Corps Gras Lipides, 16, 14-24. http://dx.doi.org/10.1051/ocl.2009.0238

[37] Zufarov, O., Schmidt, Š., Sekretár, S. and Cvengroš, J. (2009) Ethanolamines Used for Degumming of Rapeseed and Sunflower Oils as Diesel Fuels. European Journal of Lipid Science and Technology, 111, 985-992. http://dx.doi.org/10.1002/ejlt.200900025

[38] Chemical Book (2008) 1,2-OLEIN-3-LINOLEIN Basic Information. http://www.chemicalbook.com/ProdSupplierGWCB5111347_EN.htm

[39] NIST (2013) National Institute of Standards and Technology Chemistry WebBook. http://webbook.nist.gov/chemistry

[40] Wikipedia (2013) Net Present Value. http://en.wikipedia.org/wiki/Net_present_value 